\title{
Examining the neuroscience evidence for sensory-driven neuroplasticity: implications for sensory-based occupational therapy for children and adolescents.
}

Shelly J. Lane

Virginia Commonwealth University

Roseann C. Schaaf

Thomas Jefferson University

Follow this and additional works at: https://jdc.jefferson.edu/otfp

Part of the Occupational Therapy Commons

Let us know how access to this document benefits you

\section{Recommended Citation}

Lane, Shelly J. and Schaaf, Roseann C., "Examining the neuroscience evidence for sensorydriven neuroplasticity: implications for sensory-based occupational therapy for children and adolescents." (2010). Department of Occupational Therapy Faculty Papers. Paper 23. https://jdc.jefferson.edu/otfp/23

This Article is brought to you for free and open access by the Jefferson Digital Commons. The Jefferson Digital Commons is a service of Thomas Jefferson University's Center for Teaching and Learning (CTL). The Commons is a showcase for Jefferson books and journals, peer-reviewed scholarly publications, unique historical collections from the University archives, and teaching tools. The Jefferson Digital Commons allows researchers and interested readers anywhere in the world to learn about and keep up to date with Jefferson scholarship. This article has been accepted for inclusion in Department of Occupational Therapy Faculty Papers by an authorized administrator of the Jefferson Digital Commons. For more information, please contact: JeffersonDigitalCommons@jefferson.edu. 


\title{
Examining the Neuroscience Evidence for Sensory- Driven Neuroplasticity: Implications for Sensory-Based Occupational Therapy for Children and Adolescents
}

\author{
Shelly J. Lane, Roseann C. Schaaf
}

KEY WORDS

- evidence-based practice

- feedback, sensory

- neuronal plasticity

- occupational therapy

- sensation

- sensation disorders
When Ayres first presented the theory of sensory integration (SI), she grounded it in the neuroscience literature. Neuroplasticity was then, and is today, considered to be at the heart of this theory. This evidencebased review sought to critically examine the basic science literature to specifically identify evidence for the assumptions and tenets of Ayres' theory of SI. We reviewed literature between 1964 and 2005, within psychological, physiological, and biomedical areas, addressing neuroplasticity. The review focused on sensorimotor-based neuroplasticity; explored the data that addressed the links among sensory input, brain function, and behavior; and evaluated its relevance in terms of supporting or refuting the theoretical premise of occupational therapy using an SI framework (OT/SI) to treatment. Although direct application from basic science to OT/SI is not feasible, we concluded that there was a basis for the assumptions of Ayes' SI theory.

Lane, S. J., \& Schaaf, R. C. (2010). Examining the neuroscience evidence for sensory-driven neuroplasticity: Implications for sensory-based occupational therapy for children and adolescents. American Journal of Occupational Therapy, 64, 375-390. doi: 10.5014/ajot.2010.09069

Shelly J. Lane, PhD, OTR/L, FAOTA, is Professor and Chair, Department of Occupational Therapy, Assistant Dean for Research, School of Allied Health Professions, Virginia Commonwealth University, 730 East Broad Street, Suite 2050, Richmond, VA 23219; sjlane@vcu.edu

Roseann C. Schaaf, PhD, OTR/L, FAOTA, is Associate Professor and Vice Chairman, Department of Occupational Therapy, Thomas Jefferson University, Philadelphia, PA.
W hat is the neuroscience evidence that occupational therapy using a sensory integrative framework with children and adolescents will be effective? This question was designed to investigate the basic neural and developmental science literature that might support or refute the use of occupational therapy using a sensory integration (OT/SI) frame of reference for treatment.

\section{Statement of the Problem}

Participation in daily activities in part depends on the ability to process and integrate sensory information within the body and from the environment (Ayres, 1972; Bar-Shalita, Vatine, \& Parush, 2008; Bundy \& Murray, 2002; Gal, Cermak, \& Ben-Sasson, 2007). A significant number of children experience difficulty processing and integrating sensory information. In fact, Ahn, Miller, Milberger, and McIntosh (2004) found that 5\%-15\% of children in the general population of kindergarten-age children demonstrate difficulties with sensory modulation. This number is estimated to be even higher in clinical populations; $80 \%-90 \%$ of children with autism spectrum disorders have been identified as showing atypical sensory responsivity (Rogers \& Ozonoff, 2005; Tomchek \& Dunn, 2007). OT/SI is one of the most frequently requested interventions by families of children with autism spectrum disorders (Green et al., 2006; Harrington, Rosen, Garnecho, \& Patrick, 2006; Mandell, Novak, \& Levy, 2005). OT/SI is based on the belief that engagement in individually tailored activities, rich in the needed sensory stimuli, will improve the ability of the brain and nervous system to process sensory information, enhance the organization and integration of sensation, and, as a result, have a positive impact on the child's ability to participate in daily life activities (Ayres, 1972, 1979). 
In parallel with its popularity, OT/SI is a widely criticized intervention framework (Miller, 2003; Shaw, 2002). Critics have cited insufficient direct empirical or clinical evidence to support the theoretical premise that improved processing and integration of sensory information affects function and development in positive ways. Thus, the purpose of this article is to critically examine the neuroscience literature for evidence to support or refute the potential benefit of OT/SI. In preparing this material, we focused on sensory-based neuroplasticity and explored the data in the neuroscience literature that addressed the links among sensory input, brain function, and behavior. We evaluated its relevance in terms of supporting or refuting the theoretical premise of the OT/SI framework.

\section{Background Literature}

Occupational therapy using an SI framework is a widely used intervention, primarily for children (see Ayres, 1972; Green et al., 2006; Harrington, Rosen, Garnecho, \& Patrick, 2006), but also applied to the adult population (Kinnealey \& Fuiek, 1999; Kinnealey, Oliver, \& Wilbarger, 1995; Pfeiffer \& Kinnealey, 2003). Ayres' (1972, 1979) SI theory postulated that adequate processing and integration of sensory information is an important foundation for adaptive behaviors, where adaptive behaviors mean actions such as play and activities of daily living. Seven basic theoretical postulates form the foundation for the SI frame of reference for treatment (Bundy \& Murray, 2002; see Schaaf et al., 2009 , for full listing of postulates). Several of the postulates are regarding brain behavior functions. Pertinent to the topic we examined in this review, neuroplasticity, defined as the nervous system's ability to change in response to environmental input and demands, is considered to be a key postulate on which OT/SI is based.

Implicit in Ayres' early work is the idea that adequate sensory processing and integration is an important foundation for occupational role performance. Ayres hypothesized that some deficits in sensory processing and integration will result in limitations in the production of adaptive behaviors and, as such, in participation. When people experience deficits in sensory processing and integration, they struggle with the performance of everyday occupations (Ayres, 1972; Bar-Shalita et al., 2008; Bundy \& Murray, 2002; Gal et al., 2007). Adaptive responses, defined as successful interactions with the environment in response to environmental demand, can be seen as the building blocks for successful engagement and participation in occupational roles. Thus, SI/sensory processing is of concern to occupational therapists.
SI/sensory processing is the most investigated frame of reference in occupational therapy practice (Miller, 2003); most investigations of OT/SI have been clinically and behaviorally based. Although Ayres (1972) promoted SI theory as one that linked brain and behavior, the measurement tools for investigating the basic tenets of the brain-behavior link in OT/SI, as well as the impact of OT/SI on specific brain function, have only recently been realized. Thus, the scientific basis of OT/SI is currently grounded in animal research that explores the impact of environmental enrichment and single or multisensory inputs to the nervous system. As a result, this evidencebased investigation assumed a broad focus, largely outside the field of occupational therapy, and used animal and human studies (as available) that investigated the effect of sensory experiences and input on nervous system structure and function. We also examined literature that linked sensory-based interventions to the performance of skills or occupational roles. This approach carried our literature search into the examination of interventions as broad as environmental enrichment studies (e.g., rodents placed in cages with varied toys and opportunities for sensorimotor exploration; see Diamond, Rosenzweig, Bennett, Lindner, \& Lyon, 1972) and as focused as tactile input to the finger tip (Ragert, Schmidt, Alternmüller, \& Dinse, 2004).

Our emphasis was on the multiple reflections of neuroplasticity or changes in the brain linked to changes in environmental input or context. We examined studies focused on both developmental and reactive neuroplasticity, where developmental neuroplasticity refers to those changes that take place in the course of typical development and reactive neuroplasticity addresses changes that take place in response to biologically significant stimulus. Finally, many of the studies rely on animal behavior; the links to human behavior are assumptions and must be treated as such.

\section{Findings}

Before beginning the literature review, search terms were defined and refined to focus results on studies emphasizing sensory input as the independent variable and behavior or performance as an output. Details on the methodology underlying the search process are delineated in Arbesman and Lieberman (2010). Search terms used included variations of the following: neuronal or neural plasticity; neuroplasticity; neural receptors; nervous system (physiology and biochemistry, pathology); intersensory processes (includes sensory integration); sense organs (physiology and biochemistry, pathology); sensory reception; sensation (physiology); 
neural coordination; psychomotor performance; perceptual motor processes; perceptual motor learning; perception; sensory integration (keyword). As noted in the Arbesman and Lieberman (2010) article, searches were refined after review of abstracts. Abstract review was based on relevance to the topic. Most articles included in this review were research based, although a few were reviews. Although the review emphasized work accomplished in the past $15 \mathrm{yr}$; some older publications (e.g., Hubel \& Wiesel, 1965) were included because they are considered key in the field of neuroplasticity. Fifty-nine studies were identified to be of probable interest and relevance, and 50 were included in the final evidence table because they were deemed relevant to the question at hand. Table 1 is an abbreviated version of the original evidence table; the entire table can be viewed at www.ajot.ajotpress.net (navigate to this article, and click on "supplemental materials"). Of the 50 studies included, 9 were Level I, 27 were Level II, 12 were Level III, and there was 1 study each at Levels IV and $\mathrm{V}$. The evidence table presented in this article includes a sampling of all studies. The findings are summarized in the following sections by level (Levels I-IV), including key themes that might be extended to people with problems processing and integrating sensory information. Finally, in the Discussion section, we offer some interpretations and applications of this work to occupational therapists using OT/SI.

\section{Level I Studies}

The Level I studies reviewed used a randomized controlled trial design and span from 1969 to 2004. Most of this research was done using rodents, comparing the effects of enriched conditions (ECs) and deprived or impoverished conditions (ICs) on brain function. Because the studies used random assignment to experimental group, the design was strong. However, because most of studies were on animals, human application should be done with caution. Moreover, none of the studies specifically addressed OT/ SI, and as such the application of findings to clinical populations must be considered cautiously. This group of studies supports the premise that environmental enrichment alters brain structure and function in positive ways. Changes after exposure to environmental enrichment are

\footnotetext{
${ }^{1}$ Increases in both AChE and $\mathrm{CHe}$ levels reflects changes in acetylcholine activity (Giovannini et al., 2001; Gold, 2003). Some investigators use the ratio of $A C h E$ to $C h E$ because it negates the effect of tissue weight on the examination of activity changes. Acetylcholine is an excitatory neurotransmitter associated with neuromodulation and neuroplasticity, For example, an increase in acetylcholine release in the hippocampus has been documented when animals experience novelty in the environment. This increase is concurrent with improvements in cognitive performance.
}

reported in brain tissue weight, acetylcholine esterase (AChE) activity, ${ }^{1}$ total cholinesterase (ChE) levels, dendritic branching, and number of synapses.

Dendritic branching and increased number of synapses are reflections of increased neuronal interactions and a sign of structural neuronal modification and increased complexity in neuronal interactions. Changes in dendritic branching in response to enriched environments were reported by Diamond et al. (1972), Kempermann and Gage (1999), West and Greenough (1972), and Mollgarard, Diamond, Bennett, Rosenzweig, and Lindner (1971); all of these studies used rodent models. One classic example of environmental enrichment can be found in the 1972 study conducted by Diamond and colleagues. In this investigation, earlier findings documenting the effects of environmental enrichment and impoverishment ${ }^{2}$ on the rat cerebral cortex were expanded to look specifically at the effects of age and duration of exposure. Comparisons of cortical depth and cortical weight documented that the most drastic neuroplastic changes were evident in the EC rats at 25-55 days of age (roughly equivalent to 7-14 human yr) and that the findings were most pronounced in occipital and somesthetic cortex. However, of great interest was the finding that changes were also evident in the 60-to 90-day-old cohort (roughly equivalent to 16-24 yr in humans), most robustly in the occipital cortex.

In a second series of studies, in which data were included from animals exposed to the standard condition (see footnote 2) different effects between rearing conditions depended on the age of animals and segments of cortex studied. When comparing cortical depth to cortical weight, investigators found that active exploration was the critical component responsible for the changes in cortical depth (not visual stimulation alone).

These findings in rodents provide indirect support of at least one theoretical premise of OT/SI: Enriched environmental conditions facilitate neural changes. Of interest, the finding that active exploration is a necessary component of the brain changes described also lends support for a central premise of OT/SI: that active engagement (of the child) is needed to facilitate SI. Finally, these investigations also indicated that objects should be varied and that the period of exposure required was at least $1 \mathrm{hr}$ per day over a few weeks. This finding provides some

\footnotetext{
${ }^{2} E C$ offered opportunities for exploration, exercise, play, and interaction with other animals. Play items were changed regularly. IC had small cages with solid side walls and no interaction with other animals. All animals had continual access to food and water. Standard condition was added in later studies to evaluate the magnitude of the EC effects; wire cages were used so the animals could see each other, and the cages were larger than those used for IC.
} 


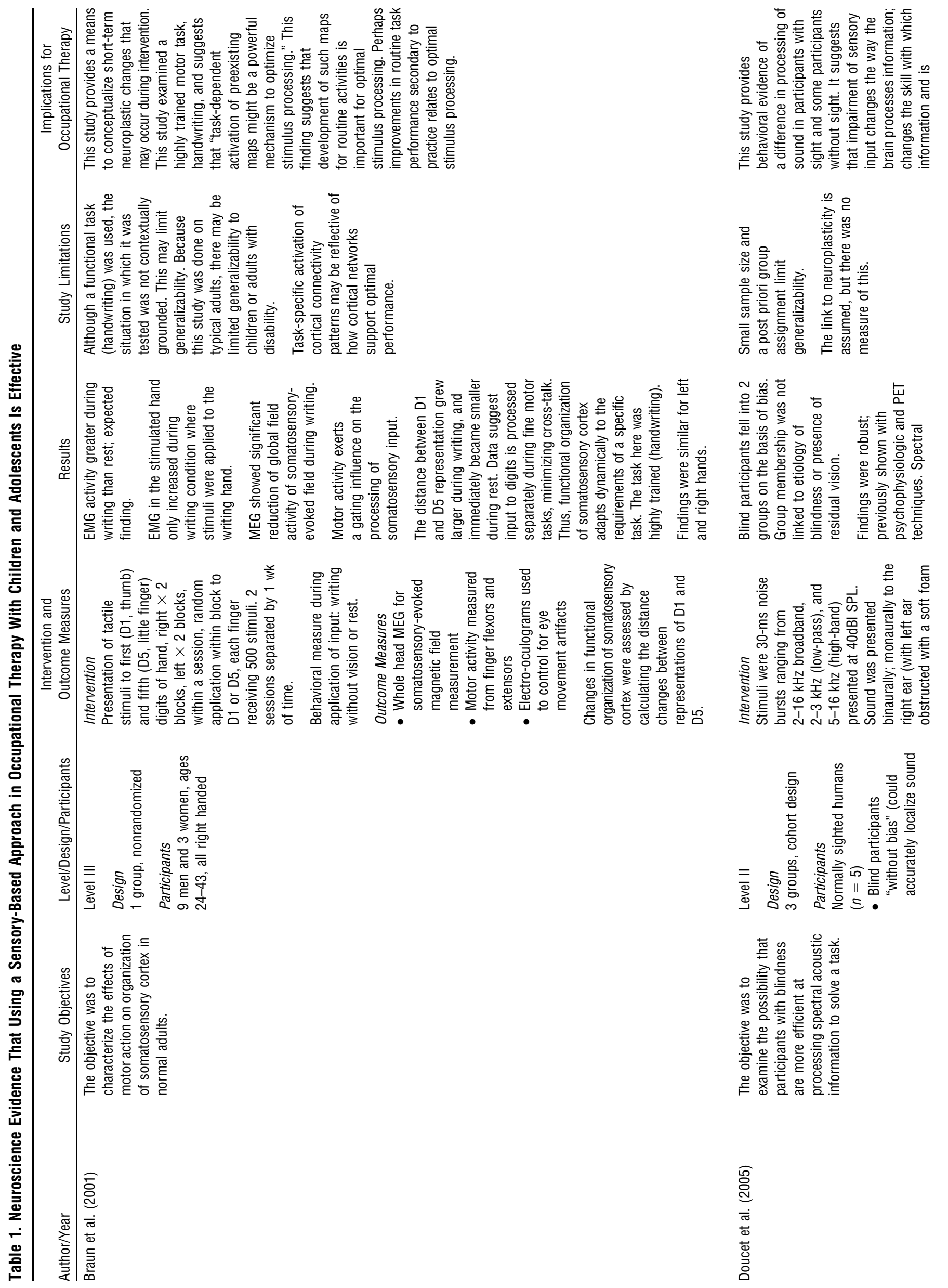


ํㅡㄹำ

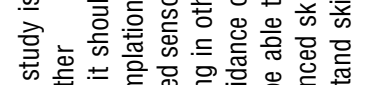
क ईँ

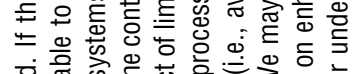

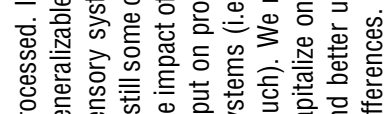

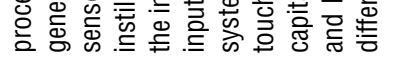

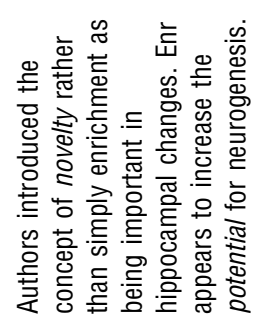
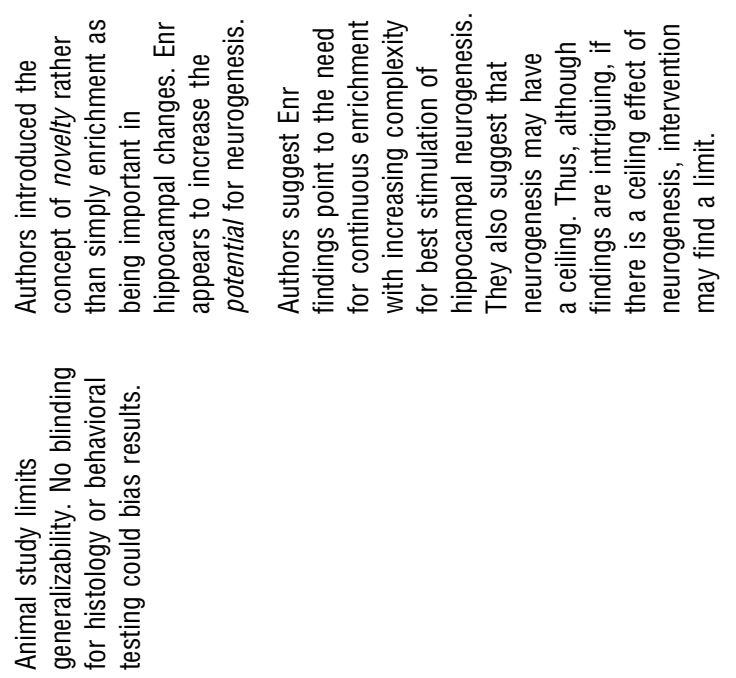

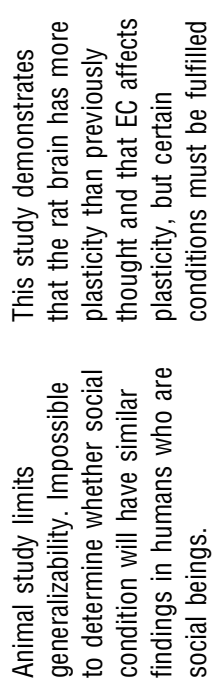

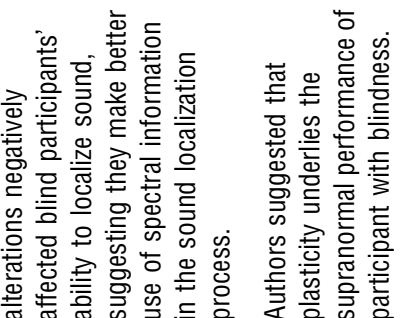

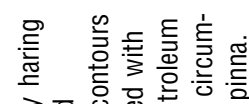

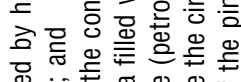

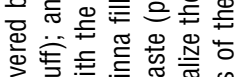

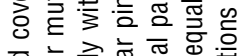

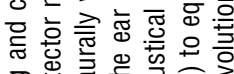

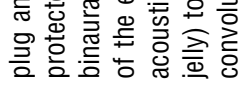

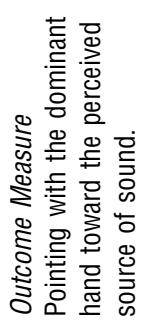

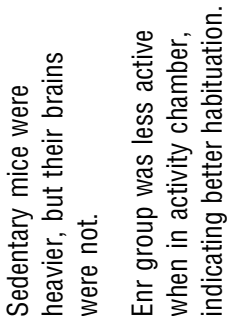

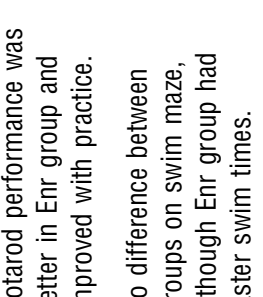

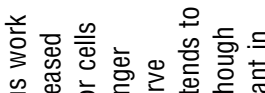

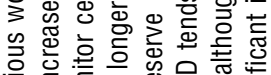

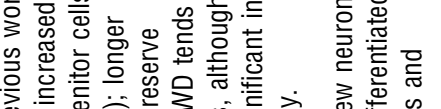
这.

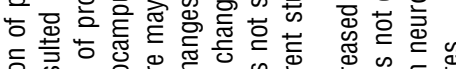

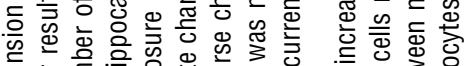

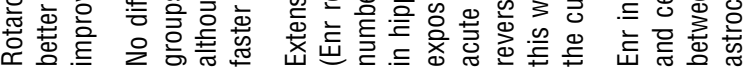

옳 은

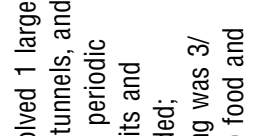

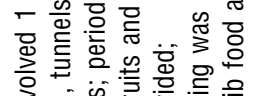

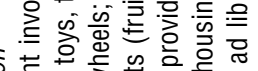

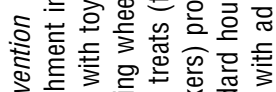

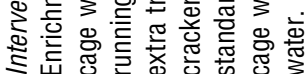

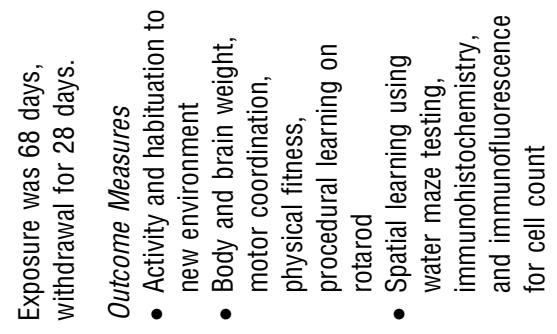

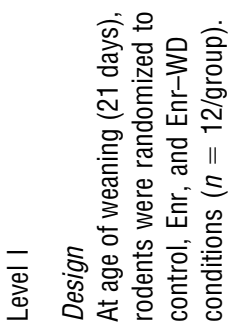

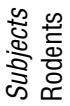

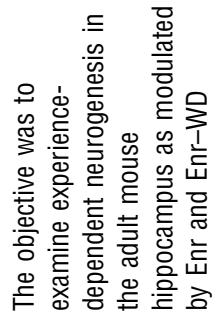

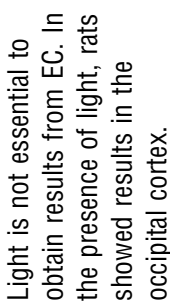
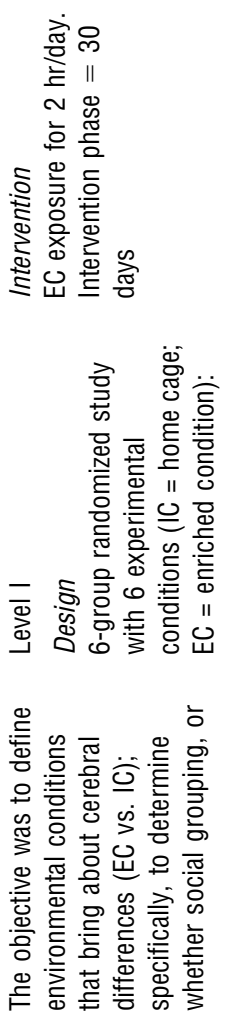
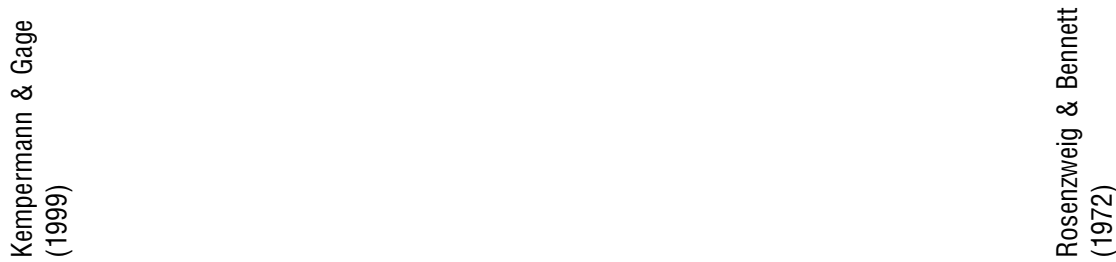

The American Journal of Occupational Therapy 


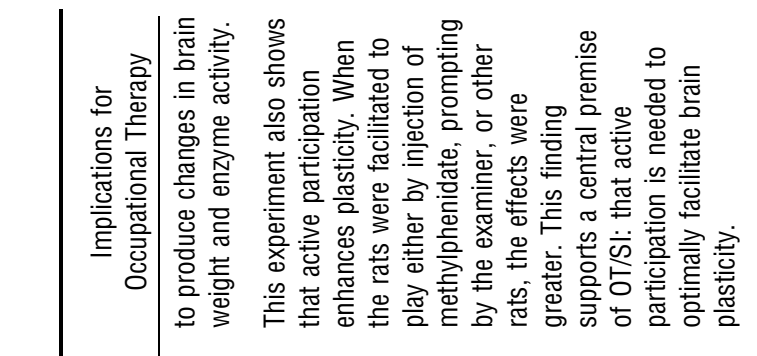

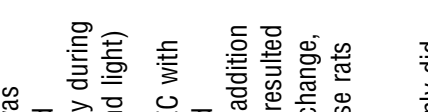

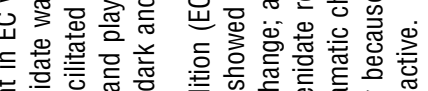

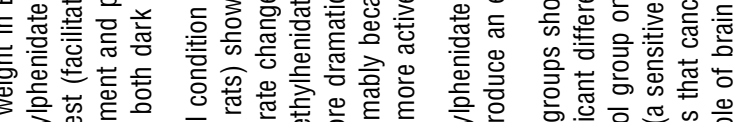

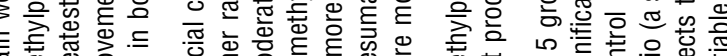

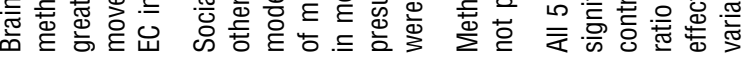

政

(1)

竞

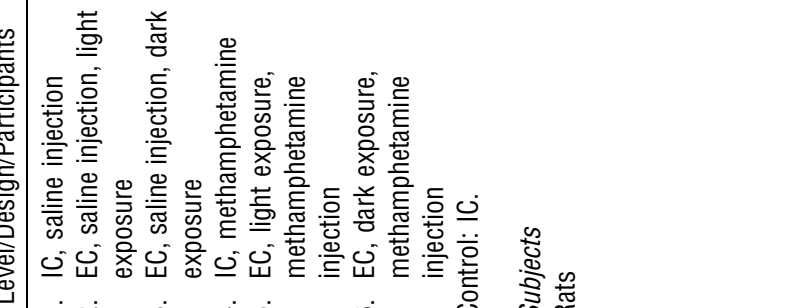

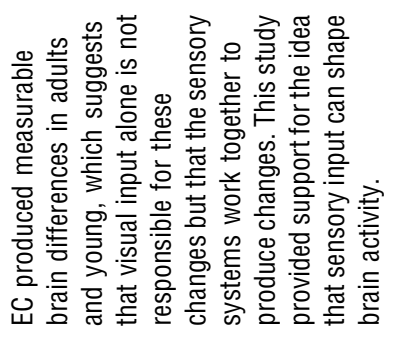

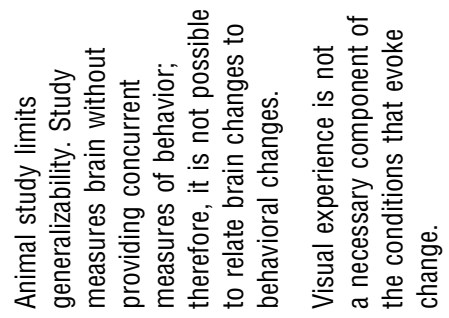

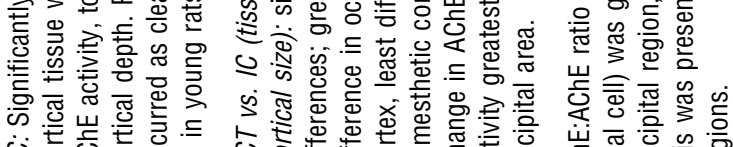

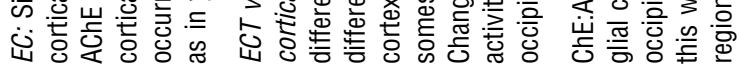

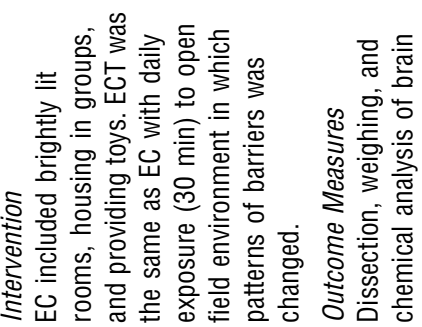

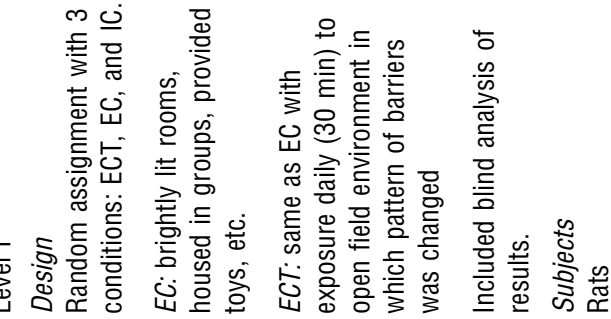

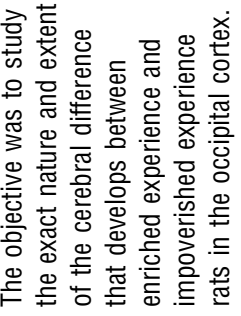




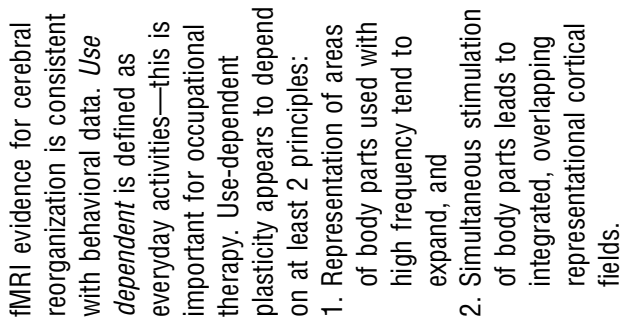

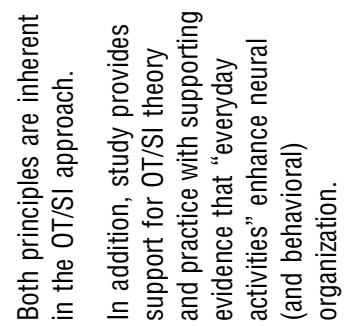

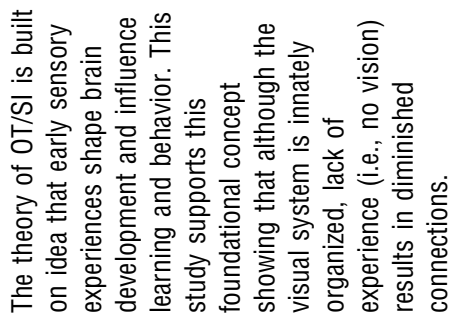

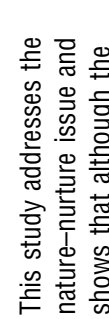

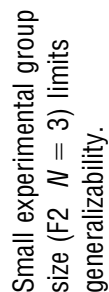

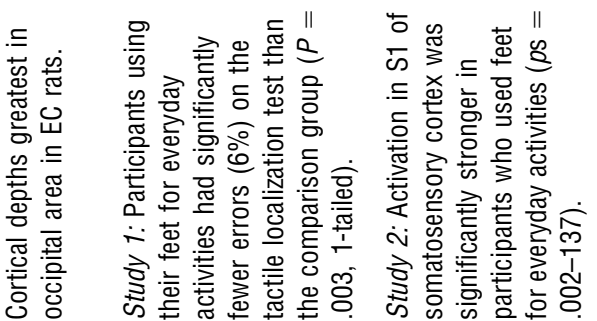

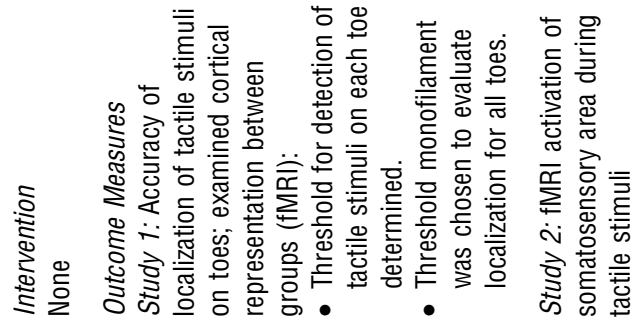

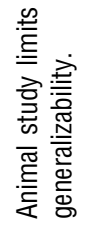
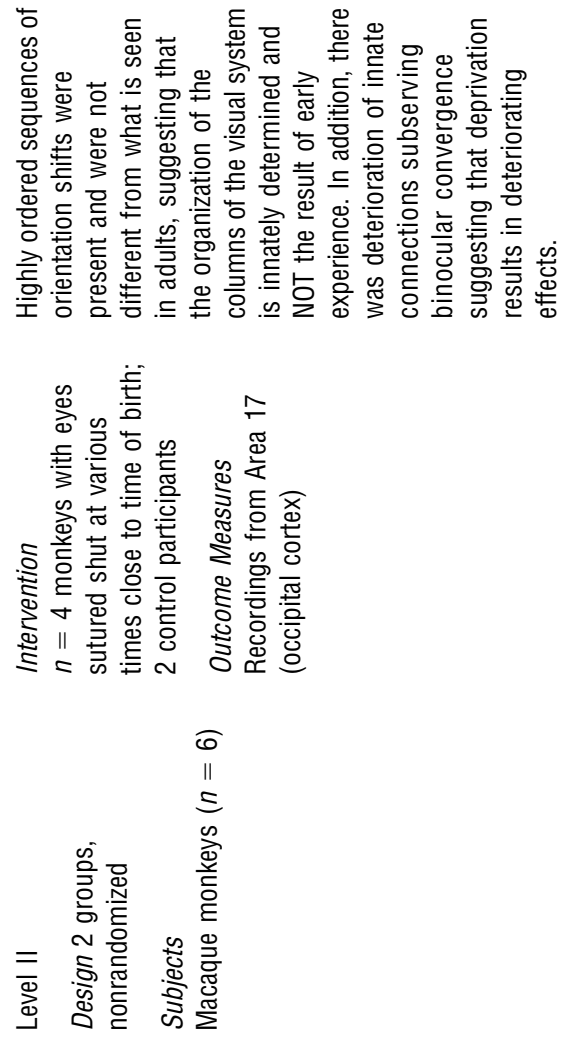

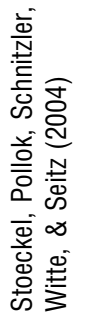




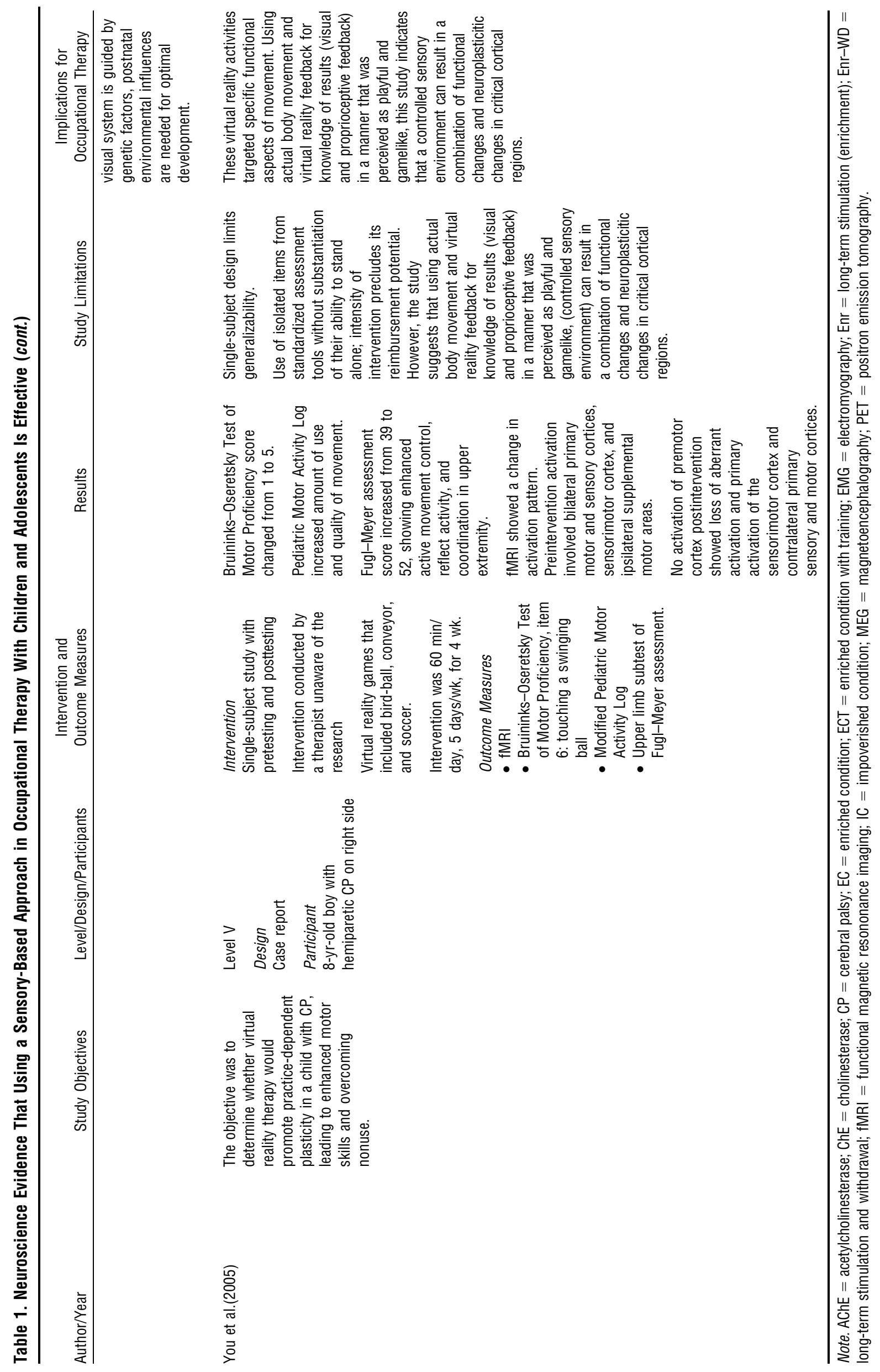


basic science data that may inform investigations related to the optimal length and frequency of intervention (also known as dosage). No behavioral measures were included in this first series of studies; no direct inference between brain changes and behavior changes can be made.

West and Greenough (1972) worked to link neuronal changes to behavioral improvements. They exposed animals to similar complex environments and found that the length and thickening of the synaptic boutons were greater in the EC rats compared with the IC rats (see footnote 2). Rats exposed to EC were also better at performing a maze task, suggesting that changes in neuronal structure are related to behavioral improvements.

Kempermann and Gage (1999) also supported the premise that ECs can alter brain activity and structure. They studied whether experience-dependent neurogenesis in the adult mouse hippocampus is modulated by longterm stimulation; they compared this condition to longterm simulation and withdrawal. Enrichment (one large cage with toys, tunnels, and running wheels and periodic extra food treats) increased the number of new neurons and cells. However, there was not increased differentiation between neurons and astrocytes, leading investigators to conclude that enrichment may increase the potential for neurogenesis. Withdrawal of the enriched environment tended to reverse the changes noted, but this reversal did not reach significance. This study adds to Kempermann and Gage's previous work by showing that longer exposure may preserve acute changes. This work also builds on the classic studies of Diamond and colleagues (1992), providing evidence that (1) exposure to enriched environments increases cell number, neurogenesis, or the potential for neurogenesis and (2) there may be a need for continuous enrichment with increasing complexity for best stimulation of hippocampal neurogenesis.

A more contemporary study of brain-behavior relationships in humans was conducted by Lacourse, Turner, Randolph-Orr, Schandler, and Cohen (2004). These authors compared physical performance of a learned task (pushing a button in a sequence with different fingers) with mental practice and no practice, using bloodoxygen-level-dependent functional magnetic resonance imaging. Investigators examined areas of cortex and cerebellum activated and performance level. Physical performance participants practiced a sequence of button presses for $1 \mathrm{wk}$; mental practice participants practiced through motor imagery; no-practice participants did not practice. Investigators found that the physical performance group demonstrated the most improvements in behavior $(121 \%$ improvement); the mental practice group demonstrated $86 \%$ improvement; and the no-practice group improved
$38 \%$. Moreover, the physical performance improvements were associated with an increase in activation of contralateral primary motor and sensory areas and the striatum along with decreased cerebellar activation. Different areas of activation change were seen in the mental practice group, suggesting different mechanisms of plasticity. The motor improvement in the physical performance group suggests that active participation, which provides somatosensory feedback, is important in motor improvement. This finding is consistent with SI theory constructs.

Additional support for the finding that active exploration, not merely seeing the stimuli, is a critical ingredient in neural changes was documented by other investigators. Examining the impact of enrichment compared with simple visual exposure, Rosenzweig and colleagues (1969) found that neuroplastic changes in the occipital cortex do not require light exposure; conversely, active exploration of the environment was crucial. In other words, the animals needed to $d o$ the exploration themselves; simply being exposed to the environment without exploring it was not sufficient to result in neuroplastic changes. In subsequent examination of what might be influencing the changes, investigators compared rats with increased activity level with rats that were prompted into activity by the experimenter. They found that the rats not needing to be prompted into activity in the ECs had the most profound cortical changes, although the extent of the effect varied depending on the cortical area measured (Rosenzweig \& Bennett, 1972). This investigation also examined AChE and ChE activity, finding changes parallel to those for cortical depth. Investigators drew several interesting conclusions from this and previous studies. First, placing rats in a large but empty cage had no effect on cortical depth or AChE activity. However, a complex environment coupled with enhanced activity resulted in profound neuroplastic changes in the brain, both in terms of cortical structure and enzyme activity. Moreover, effects were greatest if exposure to EC took place during the rat's most active period of its circadian cycle. Thus, findings indicated that active participation or exploration was crucial; changes were most profound when animals were internally driven (rather than externally prodded) to increased interaction with the environment. This finding lends support to a central premise of the OT/SI frame of reference: that active participation by the child is needed to optimally facilitate brain plasticity.

Level I studies offer the most rigorous study design, making the findings here of great interest. The fact that all but one of the studies reflected here, and all but two reviewed for this project, were conducted on animals 
makes the application to the human population somewhat tenuous. This fact can be countered by noting that there is consistency across animal models (e.g., rat, mouse, gerbil, cat), suggesting that the findings are not species specific. In broad terms, what these Level I studies point to is the importance of active exploration of complex environments for neuroplastic changes to occur in the brain; it appears to be important that engagement be ongoing rather than a single experience. Moreover, doing (physical performance) has a different effect than thinking about doing. Each of these ideas can be extrapolated, cautiously, to some of the tenets of SI theory. The sensory nature of these studies was generally broad; animals in EC conditions explored their environments, getting input through all sensory channels. In the Lacourse et al. (2004) study, human participants similarly obtained a broad range of sensory input from engagement in practice. This too is consistent with the theory of SI, as proposed by Ayres (1972). Although Ayres' original work emphasized tactile, proprioceptive, and vestibular inputs, OT/SI capitalizes on enhanced sensory opportunities in all sensory systems, consistent with that seen in these studies.

\section{Level II Studies}

Level II studies are those that compare at least two groups but in which randomization of subject to group has not been used. Examples of Level II studies include cohort and case-control designs. Of the Level II studies reviewed, 9 used human participants, 2 used nonhuman primate participants, and 16 used other animals (primarily rodent models, with some mammal models). The studies reviewed spanned from 1964 to 2005 and provide evidence that supports neuroplasticity in the central nervous system in response to sensory input. A variety of models and designs was used, including exposing animals to ECs, the results of altered or enhanced sensory input (e.g., training to enhance auditory or tactile discrimination skills; Bangert \& Altenmüller, 2003; Mercado, Bao, Orduña, Gluck, \& Merzenich, 2001; Zhang, Bao, $\&$ Merzenich, 2001), and the effects of sensory alterations (caused by congenital or induced lesions such as blindness and deafness) on brain processing and functions (Doucet et al., 2005; Hubel \& Wiesel, 1965; Stryker \& Sherk, 1975).

For the sake of brevity, the animal data are broadly summarized here. In numerous studies, strong support that sensory input (altered or enhanced) changes the way the nervous system processes information was provided (Bennett, Diamond, Krech, \& Rosenzweig, 1964; Gordon \& Stryker, 1996; Moses, Martin, Houck, Ilmoniemi,
\& Tesche, 2005; Recanzone, Schreiner, \& Merzenich, 1993). The mechanisms for these changes included increased dendritic branching (Volkmar \& Greenough, 1972), histological changes (in cell structure and function; Volkmar \& Greenough, 1972), anatomical changes (in sensory and motor maps or reorganization of brain areas), changes in cellular activation patterns (Bennett et al., 1964; Recanzone et al., 1993), and, most recently, through upregulation of genes (increasing gene expression) associated with neuroplasticity by means of brainderived neurotrophic factor (BDNF; Gómez-Pinilla, Ying, Roy, Molteni, \& Edgerton, 2002). ${ }^{3}$

As was the case for Level I studies, results from Level II animal studies are shown most consistently in response to ECs (opportunities for sensory, motor activity, and social interaction; Bennett, Rosenzweig, Diamond, Morimoto, \& Hebert, 1974; Brown et al., 2003; Kempermann, Kuhn, \& Gage, 1998) and in the visual and auditory systems (Moses et al., 2005; Recanzone et al., 1993). Neuroplastic changes are also documented in the somatosensory cortex but less consistently (Merzenich, Recanzone, Jenkins, \& Grajski, 1990; Wu, van Gelderen, Hanakawa, Yaseen, \& Cohen, 2005). The documented changes may not be global (i.e., in the entire nervous system) but rather specific to precise areas of the central nervous system - the hippocampus being one of these areas (Kempermann et al., 1998).

These same concepts are supported in the human studies, but the data are not as strong because of limitations in studying human brain tissue and processing (Bach-y-Rita, 2004; Mercado et al., 2001). The human studies do, however, demonstrate that (1) the auditory system demonstrates plasticity both in its processing (activation patterns) and cortical representation in response to auditory input (Bangert \& Altenmüller, 2003; Doucet et al., 2005; Moses et al., 2005); (2) the brain processes stimuli differently because of either training (piano playing) or ECs (Röeder, Rösler, \& Neville, 2000); and (3) processing of sensory stimuli is dynamic and flexible; that is, the sensory systems used during a task are flexible and dependent on the task presented (Russo, Nicol, Zecker, Hayes, \& Kraus, 2005). Additional human studies (Doucet et al., 2005; Sober \& Sabes, 2005) demonstrated plasticity in human sensory systems. For example, participants who have blindness demonstrate auditory system reorganization such that they become more efficient at processing auditory cues

${ }^{3}$ BDNF is a brain protein and neurotrophic factor. It can promote increased neuronal survival as well as the growth of new neurons, and it has been found in areas linked to learning and memory. 
(Doucet et al., 2005). Sober and Sabes (2005) demonstrated that the use of sensory cues was dynamic, flexible, and dependent on availability; participants could readily shift their degree of reliance on vision or proprioception, depending on what was available during a reaching task.

Level II studies reinforced outcomes related to EC identified in Level I studies and provided some interesting information about human sensory processing. They suggested that deficits in one sensory modality result in alterations in how the brain processes information in other modalities and that a typical nervous system can flexibly rely on the sensory information available within the environment to complete a task. This last point offers some support for the SI theory assumption that a successful environmental interaction promotes processing and integration of sensory information. In this case, success depended on the participant's ability to blend visual and proprioceptive strategies. Both studies used adults as participants; mature nervous systems may process information differently from developing nervous systems.

\section{Levels III, IV, and V}

Studies at Levels III, IV, and V are characterized as singlegroup, nonrandomized (III); single-subject design, case series (IV); or case reports/expert opinion (V). Those reviewed here spanned 1967 to 2005 and included many human studies, as well as studies on monkeys, kittens, and rats. Early studies of visual cortex in animal models demonstrated that the sensory systems had an innate and predetermined organization but that this organization was dependent on sensory input and experience for full expression of function (Wiesel \& Hubel, 1965, 1974). Lesions resulted in reactive morphological and physiological changes in sensory systems, suggesting that the brain reorganizes when deprived of specific sensory input. This finding was supported behaviorally in the Doucet et al. (2005) study described previously. Studies such as that of Hubel and Wiesel (1965) also showed that there were critical periods for development and restoration of function after lesion and that function did not necessarily return after a period of deprivation or lesion. Thus, there appear to be limits to degree of plasticity in organization and function.

Reactive neuroplasticity, documented behaviorally by Sober and Sabes (2005) and described earlier, was identified in the organization of human somatosensory cortex (Schaefer, Heinze, \& Rotte, 2005; Wu et al., 2005). This region of the brain was shown to adapt dynamically to requirements of a specific task; sensory input during a task resulted in changes in tactile discrimination ability. For instance, using magnetoencephalography (MEG) ${ }^{4}$ as an outcome measure, Schaefer et al. (2005) found more distant and distinct somatosensory cortical finger representation when Digits 1 and 5 were stimulated during a fine motor/cognitive task than when participants were "at rest." The plasticity was highly task dependent and dynamic in that changes were shown during task performance. These investigators concluded that changes to the somatosensory cortex are dynamic and task specific. Moreover, the fact that changes were greater during tasks that required cognitive processing suggested that dynamic plasticity can be facilitated by activation of frontal and prefrontal cortex.

The integration of visual and auditory sensory input was investigated by Moses and colleagues (2005), also using MEG. These investigators presented paired visual and auditory stimuli and noted activation in expected brain regions. Subsequently, presentation of a visual stimulus alone resulted in specific MEG responses in the auditory cortex. These investigators interpreted this finding as "associative neural plasticity" (p. 787). The demonstration in this study that the presentation of sensory information from one modality can produce brain activity in the primary cortex of another sensory modality suggested that the processing of sensation from different modalities is linked when the sensations are paired. Because our world is not one of single-channel sensory inputs, pairing of sensation is the rule, not the exception. This rule is a foundation of OT/SI; sensations are intended to be meaningfully paired such that input in one sensory modality can be used to influence processing in another modality. Because the Moses et al. (2005) study was specific to the auditory and visual systems, application to other sensory systems must be done cautiously.

Also of interest in these studies was the degree of coding engaged in by the brain. Coding refers to the process of programming activity in brain regions needed to produce the desired response. Less coding is needed for simple tasks, and the brain appears to allocate only the resources needed for the task. Examining coding of texture within the tactile and visual systems, Guest and Spence (2003) demonstrated that participants used both vision and touch in accomplishment of a task only if the task specifically required it. Integration of both sensory modalities did not take place when tasks were very

${ }^{4} \mathrm{MEG}$ is a highly sensitive imaging technique measuring the magnetic fields produced by the brain's electrical activity. 
simple, suggesting that multi-SI may depend on task difficulty or complexity.

Halder et al. (2005) examined movement repetition and practice in 10 healthy adults, using a nonskilled task (power grip using vision to control force). Electroencephalogram measurements indicated different changes in neural activity at each stage of the motor task (preparation, movement execution, and feedback integration). The researchers concluded that, in a motor task, distinct mechanisms of plasticity occur during specific stages of information processing and, with practice, motor variability decreases. This finding suggests a role for sensory feedback mechanisms in various stages of motor task execution, an example of sensory-motor integration. Moreover, using single-case design, You et al. (2005) noted that training, either actual or using virtual reality, resulted in reorganization of cortical regions that were associated with changes in performance, again suggesting a role for feedback, either actual sensory feedback or virtual feedback.

Together, the findings here suggest that neuroplasticity is dynamic and that the sensory systems interact such that pairing influences processing. Sensory strategies used are typically task and experience specific, and sensory processing strategies can be linked to stage of motor performance. Globally, these findings support the tenets of SI theory as proposed by Ayres (1972).

\section{Discussion}

This review provides direct and robust support for neuroplasticity in many brain regions in response to ECs or direct sensory input, which can be enhanced during motor activity. Findings indicated that changes in neuronal function and structure, and in some studies changes in behavioral indexes, were linked to these neural modifications. Many of the investigations reviewed here were conducted on animals; those on humans typically used adults; both of these facts limit the application of the findings to OT/SI.

Nonetheless, many interesting parallels can be drawn between these basic science studies and Ayres' (1972) SI theory. First, several of the studies reviewed described experimental manipulations that paralleled individual SI theory premises. First, the classic studies of environmental enrichment (e.g., Bennett et al., 1974, 1996; Diamond et al., 1972; Rosenzweig \& Bennett 1972; Rosenzweig et al., 1969) provided early evidence that neuroplasticity is possible and that the environment has an impact on neural structure and function. This finding has tremendous implications for occupational therapy in general and OT/SI specifically. Occupational therapists, using multiple intervention frames of reference, work to facilitate successful participation in life activities. More specific to OT/SI, successful participation in life activities is supported through the provision of an enriched environment. Using OT/SI, the "enriched environment" is designed to match expectation for performance with the client's skills and offer the "just-right challenge" to promote processing and integration of sensory information. In this respect, OT/SI differs from the foundational work on neuroplasticity, in that the enrichment is specific to the individual's needs and thus neuroplastic changes may be individually driven; however, this application warrants investigation.

Building on these classic studies, investigations of specific sensory interventions reported on in this review documented changes in central nervous system function, organization, and structure after sensory manipulations. A few key points are particularly relevant to OT/SI:

- The sensory environment and environmental opportunities or affordances generally affect brain structure and function (e.g., Bennett et al., 1974; Diamond et al., 1972; Kempermann \& Gage, 1999; West \& Greenough, 1972).

- Noted changes are often, although not invariably, documented in behavior and in brain structure and function (e.g., Halder et al., 2005; Russo et al., 2005; You et al., 2005).

- All regions of the brain do not show the same response to either specific sensory activation or enriched environments (e.g., Mercado et al., 2001).

- Changes can be task specific, making it important to be focused in terms of outcome measures (e.g., Halder et al., 2005; Recanzone et al., 1993).

- Changes are highly dynamic and seen very quickly (e.g., Pantev et al., 2003).

- Changes can be long lasting, depending on the person and the environment (e.g., Stoeckel et al., 2004).

- Some sensory systems have "critical periods" when processing changes may be easier to document or times when processing centers are more readily influenced by sensory input (e.g., Bavelier et al., 2001; Zhang et al., 2001).

- Documentation supporting interaction among sensory systems exists; stimulus pairing may be an effective intervention tool. However, it is used as needed; if the task is simple, only one sensory modality may be needed, and integration of modalities does not occur (e.g., Guest \& Spence, 2003; Hodzic, Veit, Karim, Erb, \& Godde, 2004; Moses et al., 2005; Sober \& Sabes, 2005).

- It is important to consider the cognitive demands associated with a given task because these appear to have 
an effect on motor output and sensory processing (e.g., Braun et al., 2001; Kourtzi, Betts, Sarkheil, \& Welchman, 2005).

- Rich sensory input, contextualized in meaningful activity, facilitates neuroplasticity and thus growth, development, and behavior (e.g., Gómez-Pinilla et al., 2002).

There is little question that the nervous system is plastic and that sensory input is an important mediator of this plasticity. Motor activity and interest in task also appear to be important contributors, and active engagement is seen to enhance the effects. Moreover, these studies indicated that neuroplastic changes were developmental, dynamic (reactive), and task specific. In this regard, these data provide indirect support for the use of OT/SI, which is built on the premise that active engagement in meaningful, sensorimotor activities at the just-right challenge and in a playful or meaningful context has a positive impact (by means of neuroplasticity) on processing in the nervous system (Ayres, 1972). Beyond this support, the studies reviewed inform us that multi-SI may be task specific or dependent on task complexity. This finding warrants consideration in the provision of OT/SI.

Applied to OT/SI, the message is that tasks intended to tap into more than a single sensory processing system must do so naturally if integration is to be seen. For instance, if we are hoping to integrate proprioceptive and visual inputs, then swinging on a trapeze over a bolster and targeting a pile of pillows as the drop point has the potential to be integrative; this activity combines proprioceptive (muscle contraction involved in hanging on and flexing the trunk to clear the bolster), vestibular (swinging and linear movement), and visual (identification of the target) inputs in a natural and highly motivating manner. Conversely, passive input (e.g., passive spinning, passively applied touch) would appear not to create the same affordance for integration.

In looking to address the specific question posed for our investigation (i.e., What is the neuroscience evidence that using a sensory-based approach in occupational therapy with children and adolescents will be effective?), the studies examining environmental enrichment provide the closest match to OT/SI because they offer the participant (animal or human) control over activity, novelty, and challenge; a "playful" environment; and more lifelike context (Bennett et al., 1964; Rosenzweig \& Bennett, 1972). In addition, several of the specific principles of OT/SI are at least indirectly supported. For example, OT/SI purports that intervention is best delivered in a child-directed, playful manner that allows for flexible adaptations to achievable challenges, rather than teaching to a specific task. This idea is supported in the human data demonstrating that brain processing of sensory input is flexible and dynamic and that the greatest changes come when interaction with the environment is not forced but rather self-initiated (vanPraag, Kempermann, \& Gage, 1999).

Another principle of the SI frame of reference that is supported is the notion that enriched sensorimotor experience enhances the brain's processing of information and provides a foundation for learning. This principle is demonstrated in studies showing that ECs (sensory, motor, and problem-solving opportunities) produce neuroplastic changes in areas of the brain related to learning and memory-for instance, the hippocampusthat were concurrent with behavioral improvements in learning (Kempermann \& Gage, 1999), thus supporting Ayres' (1972) original notion that sensorimotor activity provides a foundation for learning.

\section{Authors' Note}

This review of neuroplasticity literature is necessarily limited. The entire body of this literature is vast, expanding across many decades and professional areas. This project was initiated in 2005; as such, the review includes materials felt to reflect the literature up to that date. Since the conclusion of this review, additional research has been published that continues to add support to the conclusions reached in this investigation. Reflecting on these publications goes beyond the intent of this article. This is an area of growing interest, likely to continue to scaffold support for the effectiveness of sensorimotorbased interventions on improving task and role performance. It is time occupational therapists joined this movement fully, adding their collective voices to this body of neuroscience knowledge and providing the scientific evidence needed to better understand the effectiveness of OT/SI.

\section{References}

Ahn, R. R., Miller, L. J., Milberger, S., \& McIntosh, D. N. (2004). Prevalence of parents' perceptions of sensory processing disorders among kindergarten children. American Journal of Occupational Therapy, 58, 287-293.

Arbesman, M., \& Lieberman, D. (2010). Methodology for the systematic reviews of occupational therapy for children and adolescents with difficulty processing and integrating sensory information. American Journal of Occupational Therapy, 64, 368-374.

Ayres, A. J. (1972). Sensory integration and learning disorders. Los Angeles: Western Psychological Association.

Ayres, A. J. (1979). Sensory integration and the child. Los Angeles: Western Psychological Association. 
*Bach-y-Rita, P. (2004). Is it possible to restore function with two percent surviving neural tissue? Journal of Integrative Neuroscience, 3(1), 3-6.

Bangert, M., \& Altenmüller, E. O. (2003). Mapping perception to action in piano practice: A longitudinal DC-EEG study. BMC Neuroscience, 4, 26. doi:10.1186/1471-22024-26

Bar-Shalita, T., Vatine, J. J., \& Parush, S. (2008). Sensory modulation disorder: A risk factor for participation in daily life activities. Developmental Medicine and Child Neurology, 50, 932-937. doi:10.1111/j.1469-8749.2008. 03095.x

*Bavelier, D., Brozinsky, C., Tomann, A., Mitchell, T., Neville, H., \& Liu, G. (2001). Impact of early deafness and early exposure to sign language on the cerebral organization for motion processing. Journal of Neuroscience, 21, 8931-8942.

*Bennett, E. L., Diamond, M. C., Krech, D., \& Rosenzweig, M. R. (1964). Chemical and anatomical plasticity of brain: Changes in brain through experience, demanded by learning theories, are found in experiments with rats. Science, 146, 610-619.

Bennett, E. L., Diamond, M. C., Krech, D., \& Rosenzweig, M. R. (1996). Chemical and anatomical plasticity of brain. Journal of Neuropsychiatry and Clinical Neurosciences, 8, 459-470.

*Bennett, E. L., Rosenzweig, M. R., Diamond, M. C., Morimoto, H., \& Hebert, M. (1974). Effects of successive environments on brain measures. Physiology and Behavior, 12, 621-631. doi:10.1016/0031-9384(74)90212-1

*Braun, C., Heinz, U., Schweizer, R., Wiech, K., Birbaumer, N., \& Topka, H. (2001). Dynamic organization of the somatosensory cortex induced by motor activity. Brain, 124, 2259-2267. doi:10.1093/brain/124.11.2259

Brown, J., Cooper-Kuhn, C. M., Kempermann, G., Van Praag, H., Winkler, J., Gage, F. H., et al. (2003). Enriched environment and physical activity stimulate hippocampal but not olfactory bulb neurogenesis. European Journal of Neuroscience, 17, 2042-2046. doi:10.1046/ j.1460-9568.2003.02647.x

Bundy, A. C., \& Murray, E. A. (2002). Sensory integration: A. Jean Ayres' theory revisited. In A. C. Bundy, S. J. Lane, \& E. A. Murray (Eds.), Sensory integration theory and practice (2nd ed., pp. 3-34). Los Angeles: Western Psychological Association.

*Diamond, M. C., Rosenzweig, M. R., Bennett, E. L., Lindner, B., \& Lyon, L. (1972). Effects of environmental enrichment and impoverishment on rat cerebral cortex. Journal of Neurobiology, 3, 47-64. doi:10.1002/ neu. 480030105

*Doucet, M. E., Guillemot, J. P., Lassonde, M., Gagné, J. P., LeClerc, C., \& Lepore, F. (2005). Blind subjects process auditory spectral cues more efficiently than sighted individuals. Experimental Brain Research, 160, 194-202. doi: 10.1007/s00221-004-2000-4

*indicates studies that were systematically reviewed for this article and are listed in the evidence table available at www.ajot.ajotpress.net.
Gal, E., Cermak, S. A., \& Ben-Sasson, A. (2007). Sensory processing disorders in children with autism: Nature, assessment, and intervention. In R. Gabriels \& D. Hill (Eds.), Growing with autism: Working with school-age children and adolescents (pp. 95-123). New York: Guilford.

Giovannini, M. G., Rakovska, A., Benton, R. S., Pazzagli, M., Bianchi, L., \& Pepeu, G. (2001). Effects of novelty and habituation on acetylcholine, GABA, and glutamate release from the frontal cortex and hippocampus of freely moving rats. Neuroscience, 106, 43-53. doi:10.1016/ S0306-4522(01)00266-4

Gold, P. E. (2003). Acetylcholine modulation of neural systems involved in learning and memory. Neurobiology of Learning and Memory, 80, 194-210. doi:10.1016/ j.nlm.2003.07.003

*Gómez-Pinilla, F., Ying, Z., Roy, R. R., Molteni, R., \& Edgerton, V. R. (2002). Voluntary exercise induces a BDNFmediated mechanism that promotes neuroplasticity. Journal of Neurophysiology, 88, 2187-2195. doi:10.1152/ jn.00152.2002

Gordon, J. A., \& Stryker, M. P. (1996). Experience-dependent plasticity of binocular responses in the primary visual cortex of the mouse. Journal of Neuroscience, 16, 3274-3286.

Green, V. A., Pituch, K. A., Itchon, J., Choi, A., O'Reilly, M., \& Sigafoos, J. (2006). Internet survey of treatments used by parents of children with autism. Research in Developmental Disabilities, 27, 70-84. doi:10.1016/j.ridd.2004.12.002

*Guest, S., \& Spence, C. (2003). What role does multisensory integration play in the visuotactile perception of texture? International Journal of Psychophysiology, 50, 63-80. doi: 10.1016/S0167-8760(03)00125-9

*Halder, P., Sterr, A., Brem, S., Bucher, K., Kollias, S., \& Brandeis, D. (2005). Electrophysiological evidence for cortical plasticity with movement repetition. European Journal of Neuroscience, 21, 2271-2277. doi:10.1111/j. 1460-9568.2005.04045.x

Harrington, J. W., Rosen, L., Garnecho, A., \& Patrick, P. A. (2006). Parental perceptions and use of complementary and alternative medicine practices for children with autistic spectrum disorders in private practice. Journal of Developmental and Behavioral Pediatrics, 27(Suppl.), S156-S161. doi:10.1097/00004703-200604002-00014

*Hodzic, A., Veit, R., Karim, A. A., Erb, M., \& Godde, B. (2004). Improvement and decline in tactile discrimination behavior after cortical plasticity induced by passive tactile coactivation. Journal of Neuroscience, 24, 442-446. doi: 10.1523/JNEUROSCI.3731-03.2004

Hubel, D. H., \& Wiesel, T. N. (1965). Binocular interaction in striate cortex of kittens reared with artificial squint. Journal of Neurophysiology, 28(6), 1041-1059. doi:10. 1007/BF00348878

*Kempermann, G., \& Gage, F. H. (1999). Experience-dependent regulation of adult hippocampal neurogenesis: Effects of long-term stimulation and stimulus withdrawal. Hippocampus, 9, 321-332. doi:10.1002/(SICI)1098-1063(1999)9: $3<321$ ::AID-HIPO11>3.0.CO;2-C

*Kempermann, G., Kuhn, H. G., \& Gage, F. H. (1998). Experience-induced neurogenesis in the senescent dentate gyrus. Journal of Neuroscience, 18, 3206-3212. 
Kinnealey, M., \& Fuiek, M. (1999). The relationship between sensory defensiveness, anxiety, depression, and perception of pain in adults. Occupational Therapy International, 6, 195-206. doi:10.1002/oti.97

Kinnealey, M., Oliver, B., \& Wilbarger, P. (1995). A phenomenological study of sensory defensiveness in adults. American Journal of Occupational Therapy, 49, 444-451.

*Kourtzi, Z., Betts, L. R., Sarkheil, P., \& Welchman, A. E. (2005). Distributed neural plasticity for shape learning in the human visual cortex. PLoS Biology, 3, e204. doi: 10.1371/journal.pbio.0030204

*Kujala, A., Huotilainen, M., Uther, M., Shtyrov, Y., Monto, S., Ilmoniemi, R. J., et al. (2003). Plastic cortical changes induced by learning to communicate with non-speech sounds. NeuroReport, 14, 1683-1687.

*Lacourse, M. G., Turner, J. A., Randolph-Orr, E., Schandler, S. L., \& Cohen, M. J. (2004). Cerebral and cerebellar sensorimotor plasticity following motor imagery-based mental practice of a sequential movement. Journal of Rehabilitation Research and Development, 41, 505-524. doi: 10.1682/JRRD.2004.04.0505

Mandell, D. S., Novak, M. M., \& Levy, S. (2005). Frequency and correlates of treatment use among a community sample of children with autism. San Diego, CA: International Meeting for Autism Research.

*Mercado, E., Bao, S., Orduña, I., Gluck, M. A., \& Merzenich, M. M. (2001). Basal forebrain stimulation changes cortical sensitivities to complex sound. Neuroreport, 12, 2283-2287. doi:10.1097/00001756-200107200-00047

Merzenich, M. M., Recanzone, G. H., Jenkins, W. M., \& Grajski, K. A. (1990). Adaptive mechanisms in cortical networks underlying cortical contributions to learning and nondeclarative memory. Cold Spring Harbor Symposia on Quantitative Biology, 55, 873-887.

Miller, L. J. (2003). Empirical evidence related to therapies for sensory processing impairments. NASP Communique, 31, $34-37$.

Mollgarard, K., Diamond, M. C., Bennett, E. L., Rosenzweig, M. R., \& Lindner, B. (1971). Quantitative synaptic changes with differential experience in rat brain. Journal of Neuroscience, 113-128.

*Moses, S. N., Martin, T., Houck, J. M., Ilmoniemi, R. J., \& Tesche, C. D. (2005). The C50m response: Conditioned magnetocerebral activity recorded from the human brain. NeuroImage, 27, 778-788. doi:10.1016/j.neuroimage.2005. 05.017

*Nakahara, H., Zhang, L. I., \& Merzenich, M. M. (2004). Specialization of primary auditory cortex processing by sound exposure in the "critical period." Proceedings of the National Academy of Sciences of the United States of America, 101, 7170-7174.

*Pantev, C., Ross, B., Fujioka, T., Trainer, L. J., Schulte, M., $\&$ Shulz, M. (2003). Music and learning induced cortical plasticity. Annals of the New York Academy of Science, 999, 438-450.

Pfeiffer, B., \& Kinnealey, M. (2003). Treatment of sensory defensiveness in adults. Occupational Therapy International, 10, 175-184. doi:10.1002/oti.184
*Ptito, M., Moesgaard, S. M., Gjedde1, A., \& Kupers, R. (2005). Crossmodal plasticity revealed by electrotactile stimulation of the tongue in the congenitally blind. Brain, $128,606-614$.

Ragert, P., Schmidt, A., Altenmüller, E., \& Dinse, H. R. (2004). Superior tactile performance and learning in professional pianists: Evidence for meta-plasticity in musicians. European Journal of Neuroscience, 19, 473-478. doi:10.1111/j.0953-816X.2003.03142.x

*Recanzone, G. H., Schreiner, C. E., \& Merzenich, M. M. (1993). Plasticity in the frequency representation of primary auditory cortex following discrimination training in adult owl monkeys. Journal of Neuroscience, 13, 87-103.

*Renier, L., Collignon, O., Poirier, C., Tranduy, D., Vanlierde, A., Bol, A., et al. (2005). Crossmodal activation of visual cortex during depth perception using auditory substitution of vision. NeuroImage, 26, 573-580.

*Röder, B., Rösler, F., \& Neville, H. J. (2000). Event-related potentials during auditory language processing in congenitally blind and sighted people. Neuropsychologia, 38, 1482-1502. doi:10.1016/S0028-3932(00)00057-9

Rogers, S. J., \& Ozonoff, S. (2005). Annotation: What do we know about sensory dysfunction in autism? A critical review of the empirical evidence. Journal of Child Psychology and Psychiatry and Allied Disciplines, 46, 1255-1268. doi: 10.1111/j.1469-7610.2005.01431.x

*Rosenzweig, M. R., \& Bennett, E. L. (1972). Cerebral changes in rats exposed individually to an enriched environment. Journal of Comparative and Physiological Psychology, 80, 304-313. doi:10.1037/h0032978

*Rosenzweig, M. R., Bennett, E. L., Diamond, M. C., Wu, S.-Y., Slagle, R. W., \& Saffran, E. (1969). Influences of environmental complexity and visual stimulation on development of occipital cortex in rat. Brain Research, 14, 427-445. doi:10.1016/0006-8993(69)90120-6

*Russo, N. M., Nicol, T. G., Zecker, S. G., Hayes, E. A., \& Kraus, N. (2005). Auditory training improves neural timing in the human brainstem. Behavioural Brain Research, 156, 95-103. doi:10.1016/j.bbr.2004.05.012

Schaaf, R. C., Schoen, S. A., Smith Roley, S., Lane, S. J., Koomar, J. A., \& May-Benson, T. A. (2009). A frame of reference for sensory integration. In P. Kramer \& J. Hinojosa (Eds.), Frames of reference for pediatric occupational therapy (3rd ed., pp. 99-186). Philadelphia: Lippincott Williams \& Wilkins.

*Schaefer, M., Heinze, H. J., \& Rotte, M. (2005). Task-relevant modulation of primary somatosensory cortex suggests a prefrontal-cortical sensory gating system. NeuroImage, 27, 130-135doi:10.1016/j.neuroimage.2005.04.005

*Schapiro, S., \& Vukovich, K. (1970). Early experience effects upon cortical dendrites: A proposed model for development. Science, 167, 292-294.

Shaw, S. R. (2002). A school psychologist investigates sensory integration therapies: Promise, possibility and the art of placebo. Autism Today. Retrieved November 25, 2009, from www.autismtoday.com/articles/School_Psychologist_ Investigates_Sensory_Integration.htm 
*Sober, S. J., \& Sabes, P. N. (2005). Flexible strategies for sensory integration during motor planning. Nature Neuroscience, 8, 490-497.

*Stoeckel, M. C., Pollok, B., Schnitzler, A., Witte, O. W., \& Seitz, R. J. (2004). Use-dependent cortical plasticity in thalidomide-induced upper extremity dysplasia: Evidence from somaesthesia and neuroimaging. Experimental Brain Research, 156, 333-341. doi:10.1007/s00221003-1794-9

Stryker, M. P., \& Sherk, H. (1975). Modification of cortical orientation selectivity in the cat by restricted visual experience: A reexamination. Science, 190, 904-906. doi:10. $1126 /$ science. 1188372

Tomchek, S. D., \& Dunn, W. (2007). Sensory processing in children with and without autism: A comparative study using the Short Sensory Profile. American Journal of Occupational Therapy, 61, 190-200.

*vanPraag, H., Kempermann, G., \& Gage, F. H. (1999). Running increases cell proliferation and neurogenesis in the adult mouse dentate gyrus. Nature Neuroscience, 2, 266-270.

*Volkmar, F. R., \& Greenough, W. T. (1972). Rearing complexity affects branching of dendrites in the visual cortex of the rat. Science, 176, 1445-1447. doi:10.1126/science.176. 4042.1445
*West, R. W., \& Greenough, W. T. (1972). Effect of environmental complexity on cortical synapses of rats: Preliminary results. Behavioral Biology, 7, 279-284. doi: 10.1016/S0091-6773(72)80207-4

Wiesel, T. N., \& Hubel, D. H. (1965). Extent of recovery from the effects of visual deprivation in kittens. Journal of Neurophysiology, 28, 1060-1072.

*Wiesel, T. N., \& Hubel, D. H. (1974). Ordered arrangement of orientation columns in monkeys lacking visual experience. Journal of Comparative Neurology, 158, 307-318. doi:10.1002/cne.901580306

*Wu, C. W., van Gelderen, P., Hanakawa, T., Yaseen, Z., \& Cohen, L. G. (2005). Enduring representational plasticity after somatosensory stimulation. NeuroImage, 27, 872-884. doi:10.1016/j.neuroimage.2005.05.055

*You, S. H., Jang, S. H., Kim, Y. H., Kwon, Y. H., Barrow, I., \& Hallett, M. (2005). Cortical reorganization induced by virtual reality therapy in a child with hemiparetic cerebral palsy. Developmental Medicine and Child Neurology, 47, 628-635. doi:10.1017/S0012162205001234

*Zhang, L. I., Bao, S., \& Merzenich, M. M. (2001). Persistent and specific influences of early acoustic environments on primary auditory cortex. Nature Neuroscience, 4, 1123-1130. doi:10.1038/nn745 